\title{
Teaching medical ethics: the cognitive-developmental approach
}

Stephen A Goldman and Jack Arbuthnot Department of Psychology, Ohio University, Athens, Ohio, $\frac{\overline{ }}{\overline{\frac{D}{5}}}$ United States

\section{Editor's note}

Current medical education leaves many students inadequately equipped to handle ethical problems in practice. A crowded curriculum makes it difficult to devote extra teaching time to the subject. Orientation of educators to see students as 'junior colleagues' aids teaching. In this paper an experimental university course is described.

\section{Introduction}

... The only voice is that of a resident grumbling to another resident: 'This guy had just shot and killed four people and now he's in Bellevue, the armpit of mankind, and he has lower-back pain and I'm supposed to examine him and ask, politely, how he's feeling. It's dehumanizing. . . . Doctors are dreamers, man. They believe that if you pound on the chest of a ninety-year-old man, you'll save his ... life'.'

Perhaps it is impossible to teach about death. Certainly as a subject it is different from most of the scientific topics that I had laboured over in school up to that point. But between anatomy and physical diagnosis, between cellular structure and rales, nothing much, nothing of importance had been said about death. There had been a conditioning process, to be sure, that included dissection of rats, cats, and dogs as well as the intensive exposure to the cadaver in the anatomy lab. But nowhere had we sat down to talk about the real meaning of death and dying. The precipitate and bloody death of my patient that night broke through my conditioning and left me trembling on that stretcher in the empty hallway in the Chicago dawn. ${ }^{2}$

These two excerpts are illustrative of but a small proportion of the variety of moral or ethical dilemmas which face the contemporary physician. We might equally as well have chosen to begin this paper with examples of the dilemmas we face over such other issues as abortion, euthanasia, definitions of death, organ donations, enforced vaccination, artificial maintenance of life, distribution of limited medical treatments or resources, the protection of human rights in medical research, etc.

The anger and cynicism of the resident, in the first excerpt, coupled with the poignancy of the third-year medical student's experience in the second, might be unsettling to the layman, but for the medical educator the emotions are not novel. $\vec{\circ}$ The seeming inability of a resident to deal with a medical moral dilemma is distressing, but for a $\vec{\omega}$ medical student to come through two rigorous years of training in medicine, only to discover that the hours spent in the cadaver lab or the histology ir library or the lecture hall were poor background for the actual practice of medicine, is not only disturbing, $\vec{\partial}$ it is close to negligent. More importantly, it is o avoidable. The purpose of the present paper is, first, to point to the need for ethical and humanitarian education in medical schools, and, second, to describe the structure and empirically demonstrated $\frac{\Phi}{3}$ effectiveness of a course designed to meet this need.

\section{Teaching medical ethics}

The field of medical ethics has been growing steadily, and is no longer the exclusive province of educators with medical degrees. Philosophers, ethicists, psychologists, and other professionals have lent their expertise to the problem of educating the $\stackrel{\mathbb{Q}}{\mathbb{Q}}$ humanist physician. However, their suggestions $\vec{\overrightarrow{ }}$ have not met with overwhelming receptivity. In $\frac{5}{3}$ the fournal of medical education, Keyes, et al. ${ }^{3}$, offered this information: although close to 90 per: cent of the Council of Deans of Medical Schools supported the concept of greater exposure of ${ }_{\mathbb{\sigma}}^{3}$ medical students to the behavioural sciences, social sciences, and the humanities, the probability of this 3 . change occurring was seen as slim. Others have noted this serious deficiency in medical education (eg, Reynolds and Catson ${ }^{4}$ ). Maddison ${ }^{5}$ observed음 that to fail to include the medical humanities $D$ would be to fail in the 'central task of medicalo education'. Towers ${ }^{6}$ has questioned whether American medical schools are even teaching clinical ${ }^{\text {r }}$ judgement. Another critic, Abrahamson?, has 0 identified nine 'diseases of the curriculum', in-N cluding, for example, 'curriculum hypertrophy' (described as 'a curriculum increasingly crowded asco more and more content gets crammed into limited time spaces') and 'intercurrent curriculitis' (' $a \stackrel{\text { ? }}{+}$ reflection of the incompatibility or unresponsive- $T$ ness of the curriculum to concurrent societal $\frac{\vec{D}}{\vec{D}}$ problems'.) Thus, we can see that not only are $\stackrel{\mathbb{P}}{\mathbb{P}}$

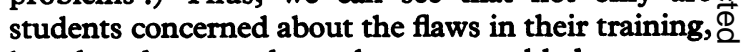
but the educators themselves are troubled.

Although there is no one solution to the problems in medical education, there has been a movement응 
toward the establishment of a branch of studies known as medical humanities. This broad category includes courses in medical ethics, as have been described in this journal in the past few years (eg, Jones and $\mathrm{Metcalfe}^{8}$; Dennis and $\mathrm{Hall}^{9}$; Clarke $^{10}$ ), as well as courses similar to the one described by Moore ${ }^{11}$ in The New England fournal of Medicine, in which the medical writings of authors such as Virginia Woolf, André Gide, Thomas Mann, and Thomas de Quincey were utilised in discussions ranging from 'Attitudes toward medical studentship' and 'The experience of illness' to 'The ethical landscape'. The need for courses such as Moore's, and the course to be described in this report, can easily be seen in the medical education literature. We can no longer deny the disillusionment and cynicism that develops in medical students as their professional training proceeds. Nor can we deny that the medical school graduate is rarely trained to deal with the difficult moral dilemmas confronting the field of medicine as a whole.

\section{STUDENT DISILLUSIONMENT}

A recent study of the 'process of disillusionment' in medical students concluded that there was a discernible pattern of discontent, both with the process of medical education and medicine in general, which occurs in the last two years of medical school. The students identified as the more susceptible to this disillusionment are those with a greater proclivity for the literary and the artistic (Schwartz, et al. ${ }^{12}$ ). That this type of student should be in greater jeopardy of losing enthusiasm for the practice of medicine is in opposition to the celebrated ideal of the 'humanist physician', the kind of physician that some feel our medical schools should be producing (Pellegrino ${ }^{13}$; Naughton ${ }^{14}$ ). Boyle and Coomb ${ }^{15}$ found that students who brought. 'romantic expectations' about the medical profession and its training methods into their first year had greater stress in coping with that crucial first year; a similar conclusion was reached by Gottheil, et al. ${ }^{16}$.

Studies of the concerns and views of first-year students are quite prevalent, yet all seem to centre on the same problems and conceptions. This is rather disquieting, as the literature on the medical student seems to centre repeatedly on these same problems (eg, in 1962-65 (Bloom ${ }^{17}$ ), 1968-69 (Rosenberg $^{18}$ ), and 1974 (Baird $\left.{ }^{19}\right)$ ). Again and again we are told that students lose their lofty ideals about medicine, undergoing a process which forces them to develop a new self-image while under stresses of numerous varieties and intensities. Funkenstein's ${ }^{20}$ extensive analysis of medical schools yielded a list of stresses that are most often experienced by medical students, and are the most harmful: difficulties in orienting to the medical school environment; marked sense of competition; scarcity of leisure time; loss of close relationshipst with faculty members; decline in the calibre of teaching; problem of challenge and response; lack? of relevance; conflicting demands; anachronistic skills and values; prolonged dependency; financing? a medical education'.

It is quite possible that some of the currenf problems in medical education may be endemic to any system of medical education that could be instituted. However, the lack of relevance than students see in their education can be minimised, if not eradicated. Ours is not the first study to examine the methods of inculcating human values intow medical education. Kepler and Saslow ${ }^{21}$ examinees the changes in attitude the medical student caros undergo after a course in human values, and theifr conclusions, though cautious, are encouraging. The $\vec{E}$ felt that the participating students may have beenf made more aware of the humanistic values iro medicine, and at the same time experiencing a decrease in the rate of the inevitable progress of cynicism. Rosenberg and $\mathrm{Weber}^{22}$, in a relateक study, examined the results of curriculum change as the University of Minnesota Medical School. Unde民 the 'new' curriculum, ranking and grades were eliminated, behavioural sciences were taught in lectures and small-group discussions, and more clinical experience and patient contact were giver to the entering student. Their results showed ar elimination of the tension and anxiety about th competitiveness, inflexibility, demand for stricg memorisation, and questionable relevance of th 'old' curriculum. Additionally, for students tested in both their freshman and sophomore years, it waş found that the 'new' curriculum students' scores on the Humanitarianism Scale didn't decline signifie cantly, while the 'old' curriculum students' scores: did. However, students in both the 'new' and the 'old' curricula were stressed in emotionally-charged situations like death ${ }^{23}$.

\section{PROFESSIONAL SOCIALISATION}

Perhaps the optimal method of arousing medica students' awareness of the great moral burden thas any physician bears is a four-year emphasis on wha? the student should expect to find upon entering the hospital world as full physician. No single course, no matter how effective, could compete with the guidance of medical students by their clinical and basic science professors (through both example and discussion). However, if this has, in fact, been taking place, the literature would not display such ex tensive discontent on the parts of both educators and those being educated.

The influence of professional socialisation in the making of the physician cannot be overestimatedo Shuval ${ }^{24}$, in her research at The Hebrew Universit 8 of Jersualem, uncovered the dual nature of the professional socialisation process. At one end of the spectrum lies the 'boy' syndrome, in which the 
medical student is pushed backward into the traditional role of the student, while at the other end lies the awarding of 'junior colleague' status. The latter orientation is a forward push in which the student is forced to adopt the professional role. The four main agents of socialisation, according to Shuval, are the physician-teachers, other hospital personnel (including nurses and technicians), patients, and student peers. All four exert varying levels of influence, although the physician-teachers' intensity of push in either direction is seen as depending on the specific atmosphere and status hierarchy of the particular medical school. The students themselves seem to exert a powerful social control, as they determine the rate at which they and their peers can legitimately adopt the professional role. Although she offers no definitive conclusions, Shuval feels that early acceptance of the professional role (namely, in the first two years) would allow for easier transition into the period of clinical training.

Other studies have pinpointed student dissatisfaction with the 'boy' role. Forty-seven per cent of students responding to a questionnaire about problems and concerns at the University of Colorado School of Medicine were 'significantly concerned' about 'feeling dehumanised', while 34 per cent resented 'being treated as though you were immature and irresponsible' (Edwards and Zimet ${ }^{25}$ ). Students at the Bowman Gray School of Medicine, when asked for sources of the stress they felt during their freshman year, selected 'long term conflict over being in a dependent, helpless role' as an important concern (Boyles and Coombs ${ }^{26}$ ). Rosenberg ${ }^{27}$ found that the undermining of the student self-image was in part caused by students' not being 'prepared to be at the bottom of a tall, formally hierarchical ladder, with time from senior staff for questions a privilege rather than a right, teaching assistants from non-medical disciplines who made them feel like second class citizens in that discipline, and head nurses who turned them away from operating rooms, delivery rooms, and sometimes even autopsies with, "You're just a freshman".' This uncertainty about self was found by Schwartz, Schwartzburg, Lieb, and Slaby ${ }^{28}$ at the Yale University School of Medicine. Over two-thirds (69 per cent) of the afore-mentioned artistically and literarily inclined medical students (the A-L group; see Note 12) and 39 per cent of the more scientifically and professionally oriented students (the P-S group) expressed feelings of depersonalisation and altered self-image. The results of these studies, and others not cited here, point to one conclusion: the medical student, from the first day of medical school, wants to be considered a 'junior colleague', not treated as a 'boy'.

The great impact that either orientation has on a medical school student body was dramatically shown by Bloom in his noted study of The State
University of New York Downstate Medical Center, Power and Dissent in the Medical School (Bloom ${ }^{20}$ ). From 1962 through 1965, at the administration's request, Bloom observed, interviewed, and administered questionnaires to faculty and students alike. He was, in this manner, able to uncover what lay beneath the tension and antagonism that would manifest itself a few years later in militant student unrest. For our purposes, one of his findings is particularly revealing - while both the voluntary faculty and the part-time clinical faculty were solidly in favour of the 'junior colleague' status for their students, the fulltime clinical faculty was split almost down the middle in their views. The majority of the basic science faculty felt that the 'boy', or 'probationary', orientation was appropriate for the students. Not surprisingly, the students felt that the part-time clinical faculty had almost as much interest in them as did their full-time professors.

Certainly, there are areas in the training of even first-year students in which the junior colleague status so strongly desired by the student can, and perhaps should, be accorded without threat to the medical educator. In particular, this greater equality of status ought to be achieved in the more philosophically-oriented pursuit of ethical training largely because of the lack of hard-and-fast rules to guide one in the resolution of ethical dilemmas. Rather, the sharing and testing of ideas and logical approaches calls for an open and 'safe' atmosphere - one in which ascribed status is not only irrelevant but inappropriate.

\section{A course in medical ethical reasoning}

In this section of the paper, we will discuss the design and empirically demonstrated effectiveness of a course in ethical (or moral) reasoning intended for use by pre-medical and medical school students. We have utilised techniques from the fields of $\delta$ moral development and moral education, course $₹$ material from the realms of literature, film, and 웅 philosophy, and the ancient Socratic educational $D$ style found in the discussion seminar. What makes this experiment unique in the field of medical $N$ humanities and medical ethics lies in its philo- of sophical and psychological bases - the theory of $N$ the development of moral reasoning pioneered by $\mathrm{N}_{\mathrm{N}}$ Dr Lawrence Kohlberg of Harvard University.

While other courses or programmes have been 0 utilised in the effort to train students of medicine to deal more effectively with the myriad moral and ? humanistic dilemmas facing both the individual $T$ physician and the field of medicine as a whole, the present course was unique in at least one major $\stackrel{\mathbb{\Omega}}{\AA}$ respect: it was based in a systematic body of $\mathbb{Q}$ psychological and educational theory and in philosophical rationale. This characteristic of the course provides several advantages. First, the

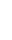


course was designed not on the basis of speculation as to what might be reasonable goals and an effective technique of instruction; rather, we drew heavily from an already substantial literature in both the theory and technique of moral education. Second, the theoretical basis of the course provided a cohesiveness to the programme of instruction in that all activity was goal-oriented; this included selection of materials, organisation of class activities, role of the instructor, evaluation of student performance, etc. And third, a clear mechanism was provided for evaluating the effectiveness of the course, both in terms of assessment devices and standards of evaluation.

THE KOHLBERG APPROACH TO MORAL DEVELOPMENT Lawrence Kohlberg, of the School of Education and the Center for Moral Education at Harvard University, has spent the past twenty years developing and testing a theory of moral development and education..$^{30}$ This theory is heavily based in Jean Piaget's ${ }^{31}$ pioneering theories of the development in children of both logical reasoning skills (in general) and moral reasoning skills (in particular). This cognitive-developmental approach to moral development has several basic and important characteristics; space limitations permit us only to mention these briefly. First, the emphasis is on cognition, or thinking, rather than on emotions (as in psychodynamic, or Freudian, theory) or learned associations (as in behavioural, or Skinnerian, theory). Thus, the focus is on the quality of reasoning and how this becomes more sophisticated with development. Second, this approach distinguishes between the structure of reasoning and its content $i e$, the interest is in how one arrives at a decision, rather than what the specific decision or opinion might be. By way of analogy, let us consider the computer: our interest is in the development of programs which enable the processing of data, rather than on the particular solutions arrived at by employing the program. A specific moral opinion (eg, 'one should not perform abortions') may be identical for a 5-year-old child and a 25-year-old medical student; however, the reasoning processes employed in reaching this solution are likely to be quite different. Third, and perhaps most basic to the cognitive-developmental approach, is the notion of stages in development of reasoning. According in this notion, the development of thinking abilities (both general and moral) occurs in an invariant sequence of stages. Initially, reasoning is simplistic and concrete; it becomes increasingly sophisticated and abstract with development. The later-appearing skills must follow the earlier abilities, as they are hierarchical reorganisations of the earlier skills. Thus, according to this model, more mature reasoning is qualitatively more sophisticated than less-well-developed thought, rather than merely being quantitatively superior.
Analogously, having learned arithmetic, the mastery $\underset{5}{\stackrel{m}{5}}$ of calculus requires more than the simple addition of more mathematical facts; it requires a much greater sophistication of logical skills - skills generally not available to the grade-school student.

Thus, the cognitive-developmental psychologist views moral judgement as an ability which differs across individuals as a function of reasoning $\mathbb{Q}$ abilities. These abilities are acquired gradually, throughout childhood and adulthood, and are determined both by general intellectual ability and ${ }_{-}^{\circ}$ the quality of the individual's socialisation ex $-\vec{\omega}$ periences. One cannot simply teach a 5-year-old $\stackrel{\circ}{\circ}$ a moral perspective which a 25-year-old has mastered only after many years of logical ex-cir periences. By way of analogy, the young child? hasn't the logical ability to understand (and, hence, $\overrightarrow{-}$ no interest in) the notion of social contracts, or the philosophical bases of documents such as the US? Constitution. But the young child can appreciate ${ }^{-}$ the threat of punishment as the basis for behavioural $D$ choice, or the marketplace morality of the exchange of goods or favours.

Table I contains a basic description of each of Kohlberg's six stages of moral reasoning, including, $\vec{c}$ for each stage, a brief explanation of what a reasoner at each stage would consider to be morally right, the reasons for doing what is right, and the social perspective of the reasoner. The six stages are divided into three basic levels. Stages $I$ and 2 . comprise the pre-conventional level, in which $\frac{}{\Phi}$ reasoning is limited to following concrete rules $\cong$ backed by power and the threat of punishment. When not prohibited, right behaviour is that which serves one's own interests, or the interests of some? other person. Stages 3 and 4 comprise the conventional level, in which what is right is that which $\overline{3}$ conforms to the expectations concerning 'good'? behaviour of the larger society or some segment of 3 . it (eg, the family or peer group). At this level the reasoner is concerned with upholding societal $\frac{}{3}$ rules, expectations, and roles, and with social $\circ$ opinion, loyalty, and gaining the approval of others. The highly egoistic orientation of Level I is replaced with subordination to the views of the larger social unit of which one is a member. Stages or 5 and 6 comprise the principled (or post-con- N ventional) level, in which what is right is deter-N mined on the basis of general or universal human ${ }_{O}$ rights, values, or principles which both the society and the individual are obligated to uphold. As ac member of society, one has a contract with society@ to uphold the rights of all members of that society. While rules are seen as necessary, they are viewedo as arbitrary; the focus is on the principles of justice upon which rules should be based. In $\frac{\mathcal{D}}{\mathcal{Q}}$ contrast to Level II, social practice should be based $\frac{\varrho}{O}$ upon morality rather than morality deriving from social practice.

A few characteristics of Kohlberg's model need to 
be mentioned in order to clarify certain aspects of the course. First, research has shown that the stages do, in fact, form an invariant and universal sequence. That is, all individuals progress through the stages in the same order. However, the rate of development may vary considerably, and few individuals reach the highest stages (most American adults are found to be at Stages 3 and 4). Rate of development and stage attained are largely $a \ddot{\Rightarrow}$ function of cultural factors: the quality of one's $\stackrel{5}{\rightarrow}$ social environment and educational experiences, $\bar{O}$ including role-taking opportunities. Such factors

Table I The six moral judgement stages

Content of stage

Level and stage What is right? Reasons for Doing right Social perspective of stage

LEVEL I -

PRECONVENTIONAL

Stage I - Heteronomous Morality
Stage 2 - Individualism, Instrumental Purpose, and Exchange
To avoid breaking rules backed by punishment, obedience for its own sake, and avoiding physical damage to persons and property.
Following rules only when it is to someone's immediate interest; acting to meet one's own interests and needs and letting others do the same. Right is also what's fair, what's an equal exchange, a deal, an agreement.
Avoidance of punishment, and the superior power of authorities.

Living up to what is expected by people close to you or what people generally expect of people in your role as son, brother, friend, etc.

'Being good' is important and means having good motives, showing concern about others. It also means keeping mutual relationships, such as trust, loyalty, respect and gratitude.
To serve one's own needs or interests in a world where you have to recognise that other people have their interests, too.
The need to be a good person in your own eyes and those of others. Your caring for others. Belief in the Golden Rule. Desire to maintain rules and authority which support stereotypical good behaviour.
Egocentric point of view.

Doesn't consider the interests of others or recognise that they differ from the actor's; doesn't relate two points of view. Actions are considered physically rather than in terms of psychological interests of others. Confusion of authority's perspective with one's own.

Concrete individualistic perspective. Aware that everybody has his own interest to pursue and these conflict, so that right is relative (in the concrete individualistic sense).

\section{LEVEL II -} Stage 3 - Mutual Interpersonal Expectations, Interpersonal Conformity
Fulfilling the actual duties to which you have agreed. Laws are to be upheld except in extreme cases where they conflict with other fixed social duties. Right is also contributing to society, the group, or institution.

\section{Perspective of the} individual in relationships with other individuals. Aware of shared feelings, agreements, and expectations which take primacy over individual interests. Relates points of view through the concrete Golden Rule, putting yourself in the other guy's shoes. Does not yet consider generalised system perspective.

Differentiates societal point of view from interpersonal agreement or motives. Takes the point of view of the system that defines roles and rules. Considers individual relations in terms of place in the system. 
Table I-continued

Content of stage

\begin{tabular}{llll}
\hline Level and stage What is right ? & Reasons for Doing Right & Social perspective of stage \\
\hline
\end{tabular}

LEVEL III - POSTCONVENTIONAL, or PRINCIPLED

Stage 5-Social Contract or Utility and

Individual Rights

Stage 6 - Universal Ethical Principles
Being aware that people hold a variety of values and opinions, the most values and rules are relative to your group. These relative rules should usually be upheld, however, in the interest of impartiality and because they are the social contract. Some nonrelative values and rights like life and liberty, however, must be upheld in any society and regardless of majority opinion.
Following self-chosen ethical principles. Particular laws or social agreements are usually valid because they rest on such principles. When laws violate these principles, one acts in accordance with the principle. Principles are universal principles of justice: the equality of human rights.

A sense of obligation to law because of one's social contract to make and abide by laws for the welfare of all and for the protection of all people's rights. A feeling of contractual commitment, freely entered upon, to family, friendship, trust, and work obligations. Concern that laws and duties be based on rational calculation of overall utility, "the greatest good for the greatest number'.

The belief as a rational person in the validity of universal moral principles, and a sense of personal commitment to them.
Prior-to-society perspective. Perspective of a rational individual aware of values and rights prior to social attachments and contracts. Integrates perspectives by formal mechanisms of agreement, contract, objective impartiality, and due process. Considers moral and legal points of view; recognises that they sometimes conflict and finds it difficult to integrate them.

Perspective of a moral point of view from which social arrangements derive. Perspective is that of any rational individual recognising the nature of morality or the fact that persons are ends in themselves and must be treated as such. 
than indoctrination into the fixed conventions of the school, the church, or the nation.' In order to stimulate this movement to a higher level of moral thought, the moral discussion approach places great emphasis on these two actions:

I) Arousal of genuine moral conflict, uncertainty, and disagreement about genuinely problematic situations. (In contrast, conventional moral education has stressed adult 'right answers', and reinforcement of the belief that virtue is always rewarded.)

2) The presentation of modes of thought one stage above the child's own. (In contrast, conventional moral education tends to shift between appeals to adult abstractions far above the child's level and appeals to punishment and prudence liable to rejection because they are below the child's level). ${ }^{36}$

Thus, the format of our course was a discussion seminar led by a trained moral educator, with preand post-course evaluation of the moral orientations of the students. Our aims were simple. Through the presentation of the various roles the physician is forced to play in today's society, and by confronting them with a battery of moral dilemmas that seemed to have no apparent ready solution, and which generated conflicting approaches from the various students, we hoped to stimulate advance in the moral reasoning stages employed by each student. By teaching the structures of reasoning rather than content (specific answers), we hoped the students would acquire skills which would enable them to become more mature and more flexible reasoners, able to respond to the unique qualities of each new situation. This is by no means an easy task; substantial cognitive changes must be made. Stimulation at a level too divergent from that of the student will result in no change. And students in moral education groups will be at several different stages, requiring individualised and differential responses by the leader.

A thorough review of the literature of medical ethics and medical humanities has not revealed any prior research utilising the Kohlberg method of moral education. The only application of the Kohlberg work we have found was a study done by Stevens and Firth ${ }^{37}$, which involved administering Rest's Defining Issues Test (an objective test of moral judgement) to a group of third-year medical students, and subsequently to a smaller group of psychiatric residents at various stages of their training. The authors concluded that medical moral education could benefit from the use of cognitive developmental approaches such as Kohlberg's. They recommended further research into such applications, as they noted that despite Kohlberg's orientation being used on myriad subject populations, 'it has yet to be applied to the medical profession, although its relevance would seem obvious'.

\section{METHODOLOGY}

The participants in this study were 15 Ohi University undergraduates, ranging in age from 18 . to 26. Fourteen different majors were represente (including two premedical students; six studente were in the Honours Tutorial programme). The course was non-graded, with either credit or no credit given upon completion of the course. Ther were no exams or papers, although there were twe essays assigned for the last two books, due to the discussion leader's discovery that a few of the students were not reading the books carefully enough for discussion. The group met twice weekly if two-hour sessions throughout the ten-week quarter Since the discussions were based on the readings of the films, the students were left little recourse but to do the reading. ${ }^{38}$

\section{INSTRUMENTS AND PROCEDURES}

At the first and last class sessions, a standardised measure of moral reasoning developed by Kohlberge was administered to all participants for the purpose्D of determining each individual's pre- and post course stage of development of moral reasoning skills (which would additionally permit an objective evaluation of the course's effectiveness). The scoring of moral reasoning protocols was based on Kohlberg's 1976 scoring procedures ${ }^{39}$. The class sessions employed the moral education techniques developed by Blatt and Kohlberg. ${ }^{39}$

\section{COURSE MATERIAL}

The course schedule was planned so that a film $\overrightarrow{\vec{D}}$ book, or specific moral dilemma was discussed at each session. The books and films were assigned in such a way as to maximise interest, and to expose. the students systematically to more difficult dil emmas as the course progressed. In that manner, Bellevue (Don Gold) served as an introduction tog the world of the inner-city hospital, while Tender $I \frac{5}{\text {. }}$. The Night (F Scott Fitzgerald), $Q B$ VII (Leon Uris), and Arrowsmith (Sinclair Lewis) were employed as portraits of the individual practitioner? all presented moral dilemmas which were discussed at length. The films - The Edelin Conviction (PBS) and abbreviated versions of Abandon Ship, and OnE The Waterfront - were also quite effective as stimulants to discussion. The dilemmas and topics discussed were myriad, including: the doctor and ${ }^{\omega}$ his feelings about death, the accountability of the physician (specifically Adam Kelno in $Q B V I I)$ research ethics and the use of a human control group (the Arrowsmith dilemma), the doctor under the law (Kelno and Edelin), the doctor and abortion (Edelin and Bellevue), and the nature of truth (On The Waterfront). However, two dis- $\frac{?}{\mathrm{D}}$ cussions stand out as the most profound, and the most troubling - the issue of triage as seen in? Abandon Ship, as a lifeboat captain must decide? which twelve passengers to throw overboard in 
order for the others to live, and Albert Camus' The Plague. The course seemed to peak around this book, as the feelings of nihilism and helplessness expressed by some of Bellevue's residents were mirrored in Dr Rieux. The essays that were written about this character were unanimous in their admiration, and many felt he was their idea of the perfect physician. The role of religion in the book and in relation to the physician were discussed, to the initial surprise and eventual satisfaction of the class.

It should be noted that the students were given a fairly extensive introduction to the Kohlberg theory, as we wanted them to be aware of what we were using as the psychological and philosophical bases for the course. They expressed great interest in this approach, and there appeared to be little apprehension about their moral reasoning stages (among other issues discussed, it was carefully explained that while the reasoning employed at higher stages may be more logically sophisticated and comprehensive, there is no inherent greater value in an individual whose stage level is higher than another's).

\section{RESULTS}

Of the fifteen students participating in this study, one did not complete the pre-course survey, and two did not complete the post-course survey. Thus, the number of participants in the data pool is twelve. The results of both surveys are shown in Table II. Each subject has four scores for each testing time ( $T_{1}=$ the pre-course survey; $T_{2}=$ the post-course survey). These are:
I) Global: This is the person's dominant or $\stackrel{\text { TI }}{=}$ 'usual' stage, and perhaps substage, based on the percentage of total moral statements; the dominant:stage is that which comprises 50 per cent or more $\stackrel{\vec{\rho}}{\vec{A}}$ of one's reasoning, while minor stages compriseo 20-50 per cent ('mixed' scores are rare, and mean no dominant stage, usually three minor stages).

2) NM: These are the scores on the non-medical $\stackrel{\mathbb{Q}}{\alpha}$ dilemmas. Both testing times consisted of two nonmedical dilemmas (different for the two testing times) and two medically relevant dilemmas. The? NM scores are weighted stage averages, referred to $\vec{\omega}$ by Kohlberg as Maturity of Moral Judgement, or $\stackrel{\rho}{S}$ MMJ; they can be multiplied by 100 to eliminate the decimals.

3) $M$ : These are the scores on the medical $A$ dilemmas, which were the same for both testing sessions. For illustrative purposes, one of the

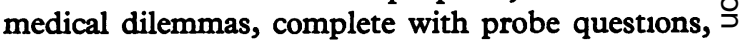
is presented in Table III.

4) Total: The MMJ scores of the medical and non-medical dilemmas combined are the total scores.

The scores were examined separately in order to permit observation of the possible situation in which advance occurred on issues raised by the medical dilemmas but not on the non-medical dilemmas (the class discussions dealt primarily with medical issues). As Table II shows, that was not the case in this study, as upward movement was shown on both categories. Change on all scores were analysed $\triangle$ for significance ( $t$ tests), as shown in Table II. $\overrightarrow{\vec{O}}$ These tests indicate positive and statistically $\exists$

Table II Changes in moral reasoning stages

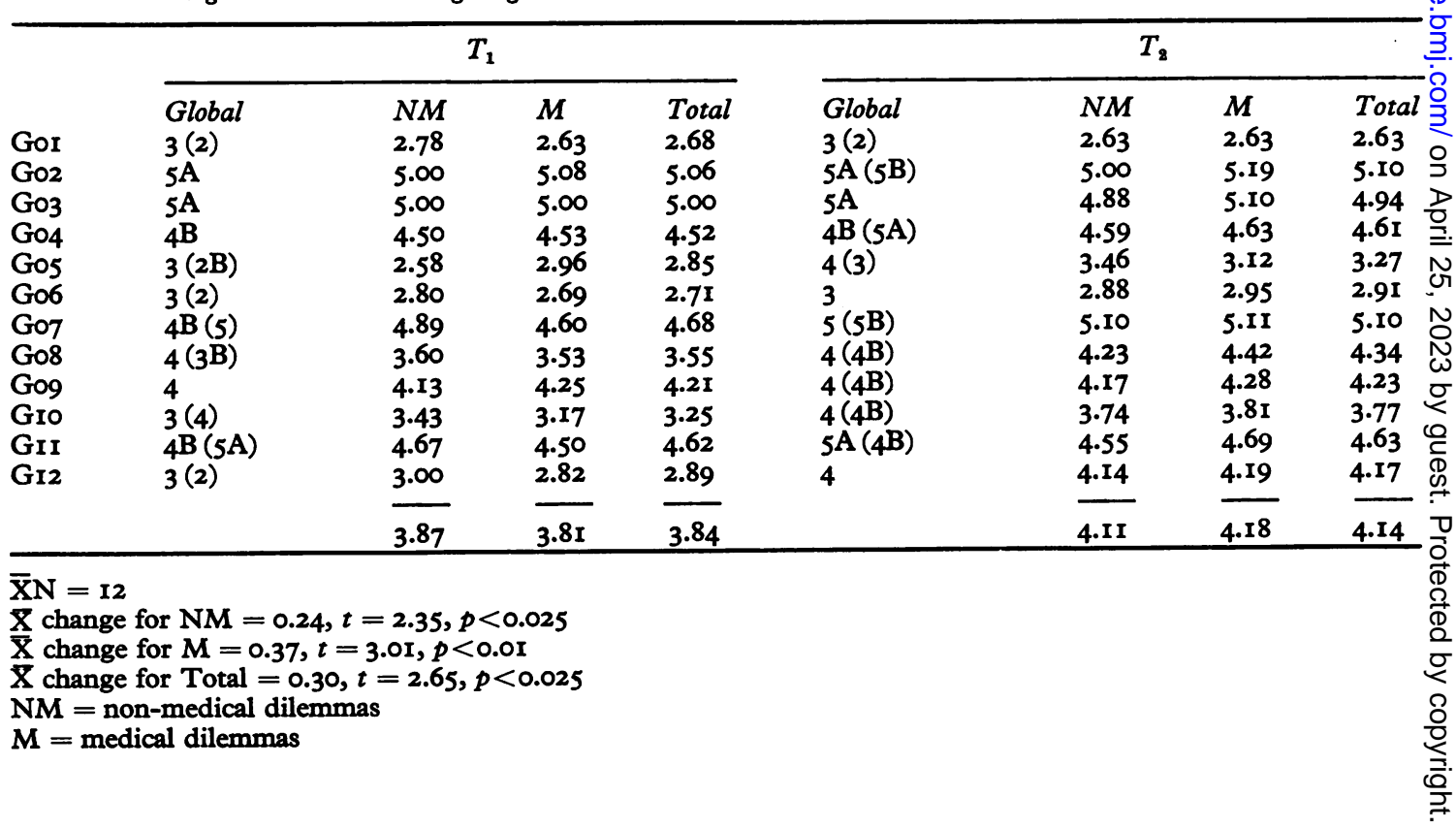


Table III One of the medical dilemmas presented to subjects, in the surveys

There was a woman who had very bad cancer, and there was no treatment known to medicine that could save her. Her doctor, Dr Jefferson, knew that she had only about six months to live. She was in terrible pain, but she was so $\Rightarrow$ weak that a good dose of a pain-killer like ether or morphine would make her die sooner. She was delirious and $\stackrel{O}{+}$ almost crazy with pain, and in her calm periods she would ask Dr Jefferson to give her enough to kill her. She saido she couldn't stand the pain and she was going to die in a few months anyway. Although he knows that mercy-을 killing is against the law, the doctor thinks about granting her request.

I) Should Dr Jefferson give her the drug that would make her die? Why or why not?

2) Should the woman have the right to make the final decision? Why or why not?

3) The woman is married. Should her husband have anything to do with the decision ? Explain.

4) Is there any sense in which a person has a duty or obligation to live when he or she does not want to, when $\vec{\circ}$ the person wants to commit suicide? Why or why not?

5) It is against the law for the doctor to give the woman the drug. Does that make it morally wrong ? Why or $\vec{\omega}$ why not?

6) Why should people generally do everything they can to avoid breaking the law ?

7) How does this relate to Dr Jefferson's case ?

significant changes for medical, non-medical, and combined measures. Generally speaking, the course was successful. When looking at the global scores, ten of the subjects showed positive movement (I/3 stage or more), while only two showed no change. The proportion of changers ( 83 per cent) exceeds that which is usually observed (30-40 per cent) in moral education programmes of this type and duration.

\section{Discussion}

This course and its materials were designed to be used in a medical school environment. We believe that the data are compelling in that we elicited an almost universal upward movement in levels of moral reasoning. In addition, based on subjective observation and unsolicited student reaction, the course seemed to be a highly effective vehicle for increasing the participants' awareness of the humanistic, as well as technical, aspects of the role of the physician in contemporary society. While these changes were effected in a sample of nonmedical students, we feel that since motivation and relevance of material are important for the effectiveness of moral education programmes, the success we have found would be duplicated, if not exceeded, with a group of medical students. For the moment, however, that must remain conjecture.

\section{IMPLICATIONS AND SUGGESTIONS}

We wish to avoid depicting the teaching of medical ethics as a panacea for the ills of medical education. However, we feel that the methods and philosophical approach that are the backbone of the course have been proven effective in the realm of medical ethics. Along with this contention we suggest that the possible results of implementing such a course in a medical school environment may have greater import than is readily apparent.

In our non-graded seminar, the discussion leader and the students are colleagues, as each individual attempts to come to grips with dilemmas 을 that have no clear-cut answers. To foster further the colleague atmosphere, the discussion leader is $\mathbb{D}$ not a lecturer; this reduces, and perhaps eliminates, $\overparen{\Phi}$ the status hierarchy of the traditional basic science $\frac{3}{0}$ course. With the absence of a traditional authority figure, the situation that Schwartz and his fellow $\vec{\varphi}$ researchers described will not exist. ${ }^{12,28}$ Thus, the A-L medical students are no longer under greater stress than the P-S medical students. In fact, it is conceivable that the traditional situation would be reversed, as the P-S students might find the ambiguity and lack of definite solutions more dis- $\frac{}{D}$ comfiting than their A-L counterparts (who have $\varrho$ less of a need for structure, for solving a problem by $\overrightarrow{\overrightarrow{0}}$ searching until the 'correct' answer is found). This 3 turnabout can be healthy for both types of students by virtue of the discovery that all are on an equal plane when confronted by a moral dilemma. Just as important is the learning of the one 'truth' that our. course offers - nothing is certain. One physician 3 feels that this is the central lesson of medicali education:

... the only certainty in medical education is 윽 uncertainty. Around the small area of recently $>$ expanded medical knowledge spreads an endless expanse of ignorance, and even the knowledge weñ have is fallible. Questioning, probing, testing by trained intellects must continue. Doubt must $N$ remain. In such uncertainty we have no alternative $\underset{\omega}{N}$ but to make ideals our basis of realism. We have to set excellence as our goal because if we cease to seekco for excellence we must fail in our purpose and the $\Phi$ future will be left to take care of itself. ${ }^{40}$

Of great importance to the effectiveness of $\frac{0}{0}$ medical/ethical education courses are the quali- $\overrightarrow{\mathbb{D}}$ fications of the discussion leader. Veatch and $\frac{?}{\mathbb{Q}}$ Sollitto ${ }^{41}$, in their report on medical ethics teaching $\frac{Q}{O}$ across the United States, judged the ideal medical ${ }_{2}$ ethics teacher to be an individual who possesses a 8 solid background in the discipline of ethics, both from 
a theoretical and clinical point of view. As there are not many who are qualified in both perspectives, they suggested a joint direction by candidates from both orientations. Veatch ${ }^{42}$ reiterated this view more recently when he spoke of the field of medical ethics as becoming an 'interdisciplinary field of study with its research tools, its theories and schools of thoughts'. Wallenmaier ${ }^{43}$, a professor of philosophy, was most insistent that medical ethics courses be taught by those trained to do so, not a medical school professor who has no background in 'value theory, logic, or philosophy of science'.

In closing, we cite the words of Anthony $R$ Moore ${ }^{44}$, a physician who in his discussion of the art of medicine saw the need for medical students to read medical books like 'Lewis's Arrowsmith and Camus's The Outsider (sic)':

I believe there is an easy, efficient, and inexpensive way to aid the art of medicine: the introduction of studies in medical ethics. . . . To tune a doctor's mind to the extrascientific patterns of thought on which the art of medicine depends: it should draw on philosophy for the study of ethical systems, and on literature and the classics for examples of moral problems, human nature and difficulties in communication. It should help doctors in their own moral dilemmas, and aid them in the understanding of the paradoxes at play in their patients.

\section{References and notes}

${ }^{1}$ Gold, D (1975). Bellevue. Dell, New York, p 91.

${ }^{2}$ Mullan, F (1976). White coat, clenched fist. Macmillan, New York, p 4.

${ }^{3}$ Keyes, J A, Wilson, P and Becker, J (1975). Fournal of medical education, 50, 319-327.

${ }^{4}$ Reynolds, R C and Carson, R A (1976). Fournal of medical education, 51, I42-143.

${ }^{5}$ Maddison, D C (1978). Medical education, 12, 101.

'Towers, B (1978). The new physician, 27, 35-36.

'Abrahamson, S (1978). Fournal of medical education, 53, $951-957$.

8Jones, J S P and Metcalfe, D H H (1976). fournal of medical ethics, 2, 83-86.

'Dennis, K J and Hall, M R P (1977). Fournal of medical ethics, 3, 183-185.

${ }^{10}$ Clarke, D D (1978). Fournal of medical ethics, 4, 36-39.

${ }^{11}$ Moore, A R (1976). The New England journal of medicine, 295, $\mathrm{I} 479-\mathrm{I} 480$.

${ }^{12}$ Schwartz, A H, Swartzburg, M, Lieb, J and Slaby, A E (1978). Medical education, 12, 182-185.

13Pellegrino, E D (1974). Fournal of the American medical association, 227, $1288-1294$.

${ }^{14}$ Naughton, J (1977). The New York State journal of medicine, 77, $1448-145 \mathrm{r}$.

${ }^{15}$ Boyle, B P and Coombs, R H (1971). Fournal of medical education, 46, 882-888.

${ }^{16}$ Cottheil, E, Thornton, C C, Conly, S S and Cornelison, Jr, Floyd, S (1969). fournal of medical education, 44, 270-277.

${ }^{17}$ Bloom, $S W$ (1973). Power and dissent in the medical school. Macmillan, New York.
${ }^{18}$ Rosenberg, P P (1971). Fournal of medical education, $\underset{+}{\stackrel{T}{F}}$ 46, $211-218$.

${ }^{19}$ Baird, Leonard L (1975). fournal of medical education, $\stackrel{?}{\cdot}$ 50, $1092-1099$.

${ }^{20}$ Funkenstein, Daniel H (1968). Fournal of medical $\stackrel{\vec{F}}{\rightarrow}$ education, 43, 883-897.

${ }^{21}$ Kepler, M O and Saslow, H (1976). Southern medical 흠 journal, 69, 2I-23.

${ }^{22}$ Rosenberg, $P$ and Weber, R G (1973). Fournal of $\stackrel{\mathbb{Q}}{\circ}$ medical education, 48, 366-368.

${ }^{23}$ In addition to educational disillusionment, there is a growing concern over the very selection of medical $\vec{O}$ students in the first place. Over a decade ago $\vec{\overrightarrow{ }}$ Korman, Stubblefield, and Martin (1968). (fournal $\vec{\omega}$ of medical education, 43, 405-4II) warned medical educators that the methods being utilised to choose $\underset{\sigma}{\sigma}$ those attending their schools were seriously flawed. or The emphasis given to MCAT scores and GPA's, they felt, almost guaranteed that the majority of $\overrightarrow{\vec{V}}$ entering medical students would be those lacking $O$ in 'such a criterion as Humanism'. Realising that $\frac{\text { ? }}{5}$ the selection methods were designed to find those students who would succeed by one standard of $\square$ success, namely good grades, they asked, 'Yet, do $\stackrel{\mathbb{D}}{\odot}$ not the needs of medicine in a changing society $\frac{\mathbb{}}{3}$ such as ours call for the education on a variety of types of medical students ?' However, as Schwartz, $\frac{\Phi}{7}$ et al. have demonstrated ${ }^{12}$, the stress of medical $\vec{\varphi}$ school selects for a certain student type, rather than for this variety.

${ }^{24}$ Shuval, J T (1975). Social science $\mathcal{E}$ medicine, 9, 413-420.

${ }^{25}$ Edwards, $T$ and Zimet, Carl N (1976). Fournal of medical education, 51, 619-625.

${ }^{26}$ Boyle, B P and Coombs, R H op. cit.

${ }^{2}$ Rosenberg, P P, op. cit., 215.

${ }^{28}$ Schwartz, A H, Swartzburg, M, Lieb, J and Slaby, A E op. cit., 183.

${ }^{29} \mathrm{Bloom}, \mathrm{S}$ W, op. cit.

${ }^{30}$ Kohlberg, L (1969). In D Goslin (Ed), Handbook of socialisation theory and research. Chicago: Rand McNally, pp 347-480.

31Piaget, J (1965). The moral judgment of the child. New : York: The Free Press.

${ }^{32}$ Kohlberg, L (I977). In T Lickona (Ed). Moral $ᄋ$ Oे development and behavior: theory, research, and social issues. New York: Holt, Rinehart \& Winston, 0 pp 3I-53.

${ }^{33}$ Faust, D and Arbuthnot, J (1978). Developmental psychology, 14, 4, 435-436.

${ }^{34} \mathrm{Colby}, \mathrm{A}$ and Kohlberg, L. Cognitive development and $\mathrm{N}$ social development. New York: Lawrence Erlbaum Associates, in press.

${ }^{35}$ Blatt, $M$ and Kohlberg, L. In $L$ Kohlberg and $E$ 岕 Turiel (Eds), Recent research in moral development, 0 Cambridge, Mass.: Moral Education Foundation.

${ }^{36}$ Hersch, R, Paoletto, D and Reimer, J (1979). Pro- $\stackrel{C}{\square}$ moting moral growth, New York: Longman.

${ }^{37}$ Stevens, $C$ and Forth, S T (1977). Canadian psychiatric association journal, 22, 44I-449.

${ }^{38} \mathrm{~A}$ more detailed description of the procedure and $\stackrel{\vec{D}}{\vec{D}}$ content of the course can be obtained by writing to $\cong$ Jack Arbuthnot, Department of Psychology, Ohio $\stackrel{\mathbb{Q}}{\square}$ University, Porter Hall 229, Athens, Ohio 45701.

${ }^{39}$ Kohlberg, L (1976). Moral stage scoring manual, Center for Moral Education, Harvard University, Cambridge, Mass. Edited June. 
${ }^{40}$ Ellis, John R (1976). Annals of internal medicine, 85, 667.

${ }^{41}$ Veatch, R M and Sollitto, S (1976). Fournal of the American medical association, 235, 1030-1033.

${ }^{42}$ Veatch, R M (1978). Fournal of the American medical association, 239, 515 .

${ }^{43}$ Wallenmaier, T E (1975). Fournal of medical education, 50, 99.

${ }^{44}$ Moore, A R (1975). The medical journal of Australia, $2,28$.

\section{Commentary}

\section{Raanan Gillon Assistant Director, Society for the study of medical ethics, London}

Although this paper gives only broad hints as to the actual content of the course in ethical reasoning which it discusses, those hints are sufficient to suggest that the course is both a stimulating and an instructive introduction to ethical analysis. The presentation of a variety of ethical dilemmas for multi-disciplinary analysis; the use of novels, plays and films as well as hypothetical (and real?) case histories in which such dilemmas occur; the inculcation of a non-hierarchic and apparently non-dogmatic approach to such analysis; all these are an admirable advance over the sort of medical education in which ethical problems are either skated around, ignored, transmuted into technical problems, or else given various mysteriously 'authoritative' solutions.

That said, Goldman and Arbuthnot's paper prompts some serious misgivings, both technical and philosophical. The technical ones would be unimportant were it not for the authors' claim for their seminars of an 'empirically demonstrated effectiveness' as a course in ethical reasoning suitable for medical students. With a sample size of twelve assessed students of whom only two were medical (pre-medical), no amount of 't-testing' for the significance of the results in relation to the individual members of this tiny group can provide 'empirically demonstrated evidence' that such results can be validly extrapolated to medical students in general. In this connection it may be of interest that preliminary impressions from the Edinburgh Medical Group's researches have suggested that medical students - perhaps because of their real life exposure to medico-moral problems are unlike other students in their approach to such problems and are predisposed to find practical or clinical solutions. They appear often to be more intuitive and emotionally involved than other students who, lacking such involvement, do discuss such issues in 'the abstract'. What effects such a difference, were it confirmed, might have on the performance of medical students in Kohlberg courses and assessments is a matter of speculation. Nonetheless the suggestion that such a difference exists makes it only more clear that on their present study Goldman and Arbuthnot certainly canno claim to have shown empirically that their Kohlberg: courses and assessments are suitable for medicas students.

Even, however, if we accept the modified but apparently valid conclusion that the large majority of twelve students (of whom two were pre-medicalक had their moral reasoning ability increased by thein Goldman and Arbuthnot course, as assessed on the Kohlberg model, serious philosophical problem? remain. The writer is not competent to assess the validity of Dr Kohlberg's Piaget-inspired twentw year research programme purporting to have dis $\overline{3}$ covered that humans develop their capacities fof making moral choices through 'an invariants sequence of stages' (outlined in Goldman and Arbuthnot's Table I). But even if Dr Kohlberg' psychological developmental findings are accurate they are of very little philosophical relevance. Thefact, if it is a fact, that humans' moral reasoning develops through a maximum of six invariant an\& invariantly consecutive stages does not help us tक्ष decide which of these stages represents the mos valuable, important or true of the various ethicat theories or stances which they incorporate. Middle age invariantly comes after youth but this does not help us decide which is more valuable or importanto One would wish, in Goldman and Arbuthnot's defence, to accept their assertions that their course is concerned not with the content of their students $\frac{D}{D}$ moral reasoning but with its 'quality' and in par尺 ticular with its flexibility and with its logica $\overrightarrow{\vec{b}}$ sophistication. Then their avowed aim of incul 3 cating as high a Kohlberg moral reasoning stage as possible could be interpreted as an attempt to do no. more than teach reasoning skills of some logica complexity. However, if one examines their sum mary of the six Kohlberg stages (Table I) one finds little about quality or sophistication of reasoning on the other hand there are substantive differences? in content between the stages. Thus stage I may reasonably be interpreted as summarising (roughly!) the ethical theory called egocentric hedonism $\frac{D}{0}$ Stage 2, still presumably primitive and undesirable from the Kohlberg viewpoint, adds to the ego- N centricity of stage I both a recognition of the egocentric objectives of others and a concept of fairness. Taken together these substantive $\mathrm{com}^{-\omega}$ ponents of stage 2 suggest an ethical theory which its contemporary advocates might label 'enlightened self interest' and defend with considerable 'sophistication', 'quality of reasoning' and 'higher orderlogical skills'. Those who doubt this will find examples of such defences in David Gauthier's $\overrightarrow{\mathbb{D}}$ collection Morality and Rational Self-Interest $-\frac{?}{\square}$ indeed Jesse Kalin's contribution may be seen as a $\propto$ sophisticated defence of an ethical egoism which probably lies full square in stage $I$, right at the bottom of Kohlberg's scale! 